\title{
IMPACTS OF SPARTINA ALTERNIFLORA EXPANSION ON LANDSCAPE PATTERN AND HABITAT QUALITY: A CASE STUDY IN YANCHENG COASTAL WETLAND, CHINA
}

\author{
ZHANG, H.-B. ${ }^{*}$ - LIU, Y.-Q. - XU, Y. - HAN, S. - WANG, J. \\ School of Urban and Planning, Yancheng Teachers University, Yancheng 224007, China \\ (e-mails: liuyuqing02102123@163.com-Y.Q.Liu; xeniayy@hotmail.com-Y.Xu; \\ hanshuang412@163.com-S.Han; wangjjsyctu@163.com-J.Wang) \\ *Corresponding author \\ e-mail: yctuzhanghb@163.com; phone: +86-133-7526-7876 \\ (Received 24 $4^{\text {th }}$ Dec 2019; accepted 22 $2^{\text {nd }}$ May 2020)
}

\begin{abstract}
Yancheng National Nature Reserve (YNNR) in Jiangsu province is the largest wintering habitat for red-crowned cranes (Grus japonensis) in the world. However, the Spartina alterniflora ( $S$. alterniflora) expansion had caused a series of ecological problems. In the paper, by using ETM + images as data source, GIS technology and the InVEST model were used to analyze the influence of $S$. alterniflora expansion on the landscape pattern and habitat quality through scenario simulation. We found that: from 2000 to 2020, under the current conditions, the percentage of landscape (PLAND) of $S$. alterniflora marsh would increase from $17.525 \%$ to $51.522 \%$, which would result in a risk of extinction for the Suaeda salsa (S. salsa) marsh; the habitat quality index (Q) would be decreased from 0.8183 to 0.7074. Under the condition of removing S. alterniflora, the PLAND of S. salsa marsh would be restored to $43.8317 \%$, and the Q would be increased to 0.9463 . Under the condition of controlling S. alterniflora expansion, the PLAND of $S$. alterniflora marsh would be decreased to $8.678 \%$, the PLAND of $S$. salsa marsh would be restored to $43.8653 \%$, and the Q would be increased to 0.9198 . The results would be beneficial to the management of the YNNR.
\end{abstract}

Keywords: scenario simulation, habitat protection, species invasion, InVEST, the YNNR

\section{Introduction}

The Yancheng coastal wetland is located in the middle of the Jiangsu coast. It is one of the most typical and representative distribution areas of muddy coastal wetlands integrating tidal flats, tides, rivers, salt marshes, Phragmites australis ( $P$. australis) marshes, and Spartina alterniflora (S. alterniflora) marshes in China and in the world. It is the first world natural heritage site in Jiangsu province, the first natural heritage site of a coastal wetland in China, and the second such site in the world. Yancheng Coastal Wetland has basically maintained its natural ecological structure and function (Liu et al., 2003) with the Yancheng National Nature Reserve (YNNR) and Jiangsu Dafeng Elk National Nature Reserve. There are 17 species listed in the International Union for Conservation of Nature (IUCN) red list of species. It is an irreplaceable natural habitat that provides protection for rare and endangered migratory birds and has global value.

$S$. alterniflora is a perennial herb that is native to the west coast of the Atlantic and the Gulf of Mexico. It plays an important role in protecting coastal wetlands from wave erosion because of its rapid spread and great ability to promote silt deposition (Ayres et al., 2002). Therefore, S. alterniflora was successfully introduced in Yancheng coastal wetlands in the 1980s. In the 1990s, a large community was formed and rapidly expanded, and the species has become the dominant vegetation in the YNNR. The invasion of $S$. alterniflora has caused significant changes to the native ecosystems, including alteration of habitat structures, the extinction of native species, and altered 
ecosystem productivity (Vitousek et al., 1996; Pimentel et al., 2000; Neira et al., 2006; Liao et al., 2008; Wang et al., 2008). Invaders can have spatially variable effects on the ecosystem structure and function through their exploitation of different patches as they advance across landscapes (Sharp et al., 2019). The expansion of S. alterniflora has reduced the living space of other intertidal organisms and caused negative ecological effects (Liu et al., 2009). Cranes and other rare species primarily forage in P. australis marshes and S. salsa marshes in Yancheng Coastal Wetland (Wang et al., 2019). The landward expansion has led to the loss and fragmentation of $S$. salsa marshes, which is used as a wintering habitat for cranes.

The impact of the invasion of S. alterniflora on the coastal wetlands has become an important research topic in recent years (Liu et al., 2007; Schindler et al., 2013; Ayres et al., 2004). However, most studies focus on the population scale. S. alterniflora competes with native plants, and the habitat fragmentation of $P$. australis communities has led to the forced miniaturization of Paradoxornis heudei, which depends on these habitats (Dong et al., 2010). The invasion of $S$. alterniflora has resulted in the gradual shrinking of the habitat areas of $S$. salsa. This has led to significant changes in the spatial distribution pattern of the nesting sites of Saunders's gull during the breeding period, which has had a significant impact on the population (Liu et al., 2009). The invasion has also led to a large reduction of suitable wetland areas for red-crowned cranes to live and feed, which has had a certain impact on the dynamic distribution of their wintering population (Liu et al., 2016; Wang et al., 2019).

The mentioned study clarified the influence of S. alterniflora expansion on population dynamics, which could provide a scientific basis for the protection of specific population. With the extensive application of remote sensing technology, studies have been widely carried out on the impact of $S$. alterniflora expansion on the landscape pattern (Zhang et al., 2013; Wang et al., 2014; Fang et al., 2014). In this context, the InVEST model was used to analyze the impact of $S$. alterniflora expansion on habitat quality at the landscape scale. We examined how much the expansion could extend in the study area in the future and what it could look like. From the perspective of sustainable development of nature reserves, we also examined the possible trends of landscape change and habitat quality development of nature reserves in the future, which would provide reference for the sustainable construction and management of the research area.

\section{Material and methods}

\section{Study area}

The YNNR is located at $32^{\circ} 20^{\prime} \mathrm{N}-34^{\circ} 37^{\prime} \mathrm{N}$ and $119^{\circ} 29^{\prime} \mathrm{E}-121^{\circ} 16^{\prime} \mathrm{E}$ (Fig. la). It covers $4.533 \times 10^{5} \mathrm{hm} 2$, and the length of the coastline is $582 \mathrm{~km}$. The YNNR is located in a transition zone between a subtropical zone and a warm temperate zone. It was established in 1983 and upgraded to a national nature reserve in 1992. It is an important member of the World Biosphere Reserve, the Northeast Asia Crane Network, and the East Asia-Australia Wader Migration network and has been added to the list of Wetlands of International Importance.

The core zone of the YNNR has a total area of $1.92 \times 10^{4} \mathrm{hm}^{2}$ and reaches the Xinyang River in the north, the Doulong River in the south, the seawall road in the west, and the edge of mudflats in the east (Fig. 1b). It is a typical tidal muddy wetland. The core area of the YNNR is divided into north and south areas by Zhonglugang Road. In the north, a project was carried out for the artificial restoration of $P$. australis 
marshes in an area that covers about $0.52 \times 10^{4} \mathrm{hm}^{2}$. The southern part is weakly affected by human activities, and the evolution of the landscape pattern is mainly affected by natural factors such as climate, topography, hydrology, soil, and vegetation. It has become a typical area with natural conditions and covers about $1.11 \times 10^{4} \mathrm{hm}^{2}$. The southwest is an aquaculture pond with an area of $0.29 \times 10^{4} \mathrm{hm}^{2}$. In this study, the area of natural conditions was selected as the study area (Fig. 1c), in which the development of S. alterniflora is typical and well preserved.

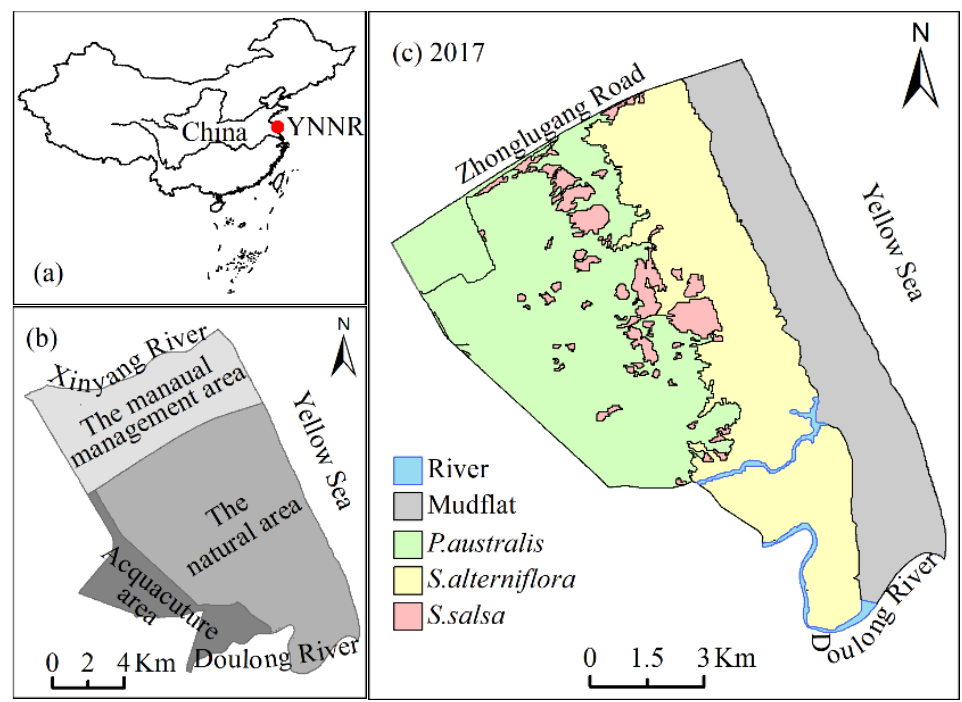

Figure 1. The location and scope of the study area. (a) The Yancheng National Nature Reserve $(Y N N R)$ is located in the central east coast of China. (b) The scope of the core zone of the YNNR. (c) Landscape classification of the study area in 2017

\section{Data source and landscape type}

The ETM + remote sensing images in May 4, 2000, May 21, 2006 and September 24, 2011 were used as data sources. The ETM + remote sensing image includes seven multispectral images and one panchromatic image, and the former has a resolution of $30 \mathrm{~m}$ while the latter has a resolution of $15 \mathrm{~m}$. In ENVI 5.0, on the basis of atmospheric correction and geometric correction, the methods of the unsupervised classification and the decision tree classification were used to interpret the remote sensing images. In ArcGIS 10.0, the landscape type maps were completed, as shown in Figure 2. A coastal wetland is a complex natural complex between the land and sea with various types of ecosystems. The landscape in the core area of the YNNR is divided into three categories: natural wetland, artificial wetland and non-wetland. The division is based on the landscape characteristics of the study area and the definition of the Convention on Wetlands of International Importance as a Waterfowl Habitat. The natural wetland includes five types: P. australis marsh, S. salsa marsh, S. alterniflora marsh, mudflats, and rivers. The artificial wetland are aquaculture ponds, and the non-wetland area are dams.

\section{Landscape pattern analysis}

To analyze landscape pattern change, FRAGSTATS 4.2 was developed by the United States Department of Agriculture (USDA). Six landscape indices describe the characteristics of the landscape structure composition and spatial configuration of the 
Percentage of Landscape (PLAND): the Fractal Dimension Index (FRAC), Shannon's Diversity Index (SHDI), Landscape Dominance Index (LDI), Landscape Evenness Index (SHEI), and Aggregation Index (AI). The landscape transfer matrix can also help to explain how the composition and types of landscape change. It can also comprehensively and concretely describe the structural characteristics of the landscape and the changes of quantity and direction between landscape types.

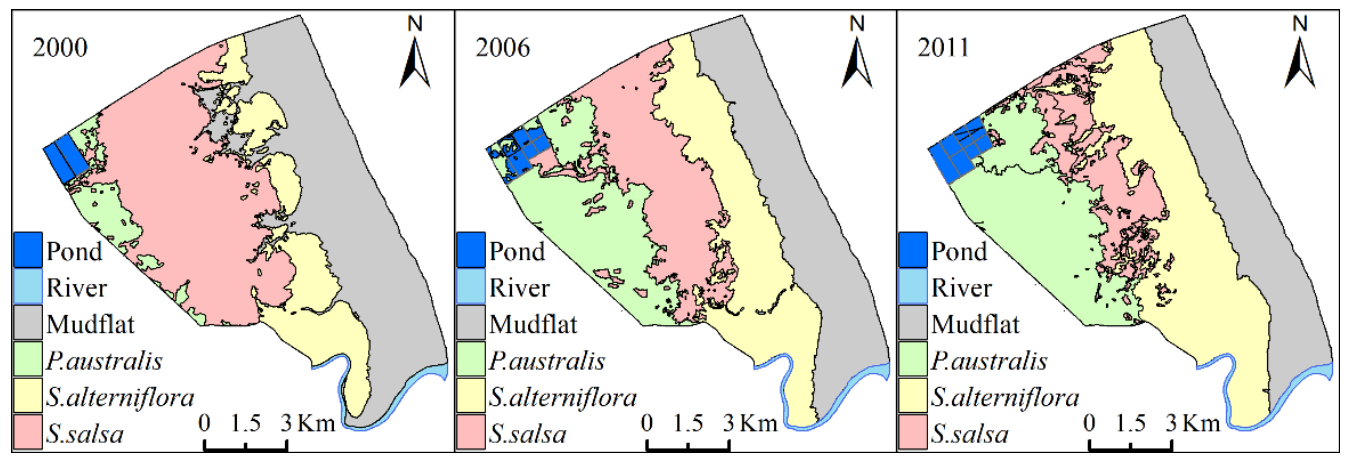

Figure 2. Landscape type maps in 2000, 2006 and 2011

\section{Landscape change scenario simulation}

A mechanism model ( $\mathrm{V}$ 1.0) was developed for the landscape pattern of Yancheng coastal wetland based on the soil moisture and salinity processes (Software copyright: No.01678102, 2017). The model was designed by using the platforms ArcGIS 10.0 and MATLAB 2008. It can dynamically display the regional landscape changes and explain their mechanisms from the perspective of ecological processes (Zhang et al., 2014)

The system is composed of four parts. First, the main program reveals the relationship between landscape pattern change and ecological process. The second is that time function requires continuous changes in time and can realize the landscape simulation of any time (unlimited time interval) in the study area. The third part is visual expression, and the fourth part is used to call commands.

The model includes the threshold parameters of soil moisture and salinity of different types of landscapes and their annual change parameters, which are driven by different factors (Zhang, 2018). In this study, the soil moisture and salt parameters were adjusted based on the landscape types and soil moisture and salinity in 2011 to simulate the landscape pattern changes in 2020 under different scenarios. The change of the landscape pattern was simulated under three scenarios: the current situation (Scenario A), S. alterniflora would continue to expand in accordance with the present natural conditions and without any interference. Removal of Spartina alterniflora (Scenario B), $S$. alterniflora would be removed completely through certain artificial measures. Ecological restoration (Scenario C), S. salsa marsh would be restored and the expansion of $S$. alterniflora to $S$. salsa marsh would be controlled by techniques.

In the study, we used the images of 2017 to verify, and the overall accuracy of the simulation was $82.03 \%$. The Kappa coefficient value was 0.72 . When the Kappa coefficient was greater than 0.7 , the consistency between the simulation result and the real value was considered to be quite satisfactory (Monserud and Leemans, 1992; Landis and Kochm,1997). 


\section{Habitat quality assessment}

The Integrated Valuation of Ecosystem Services and Trade-offs (InVEST) model were developed by Stanford University, The Nature Conservancy (TNC), and World Wide Fund for Nature or World Wildlife Fund (WWF) to simulate the change of quality and value of ecosystem processes under different land cover scenarios. The biodiversity module in the InVEST model can assess changes in habitat quality in different times. In the model, habitat quality is generally affected by threat factors, habitat suitability, and ecological protection policies. Relevant parameters are shown in Tables 1 and 2.

Table 1. Attribute table of ecological threat factors

\begin{tabular}{c|c|c|c}
\hline Threat factors & Maximum impact distance $\mathbf{( k m )}$ & Weight & Linear correlation of regression \\
\hline Aquaculture pond & 1 & 0.6 & 0 \\
River & 3 & 0.4 & 1 \\
Road & 5 & 0.8 & 1 \\
S. alterniflora & 3 & 0.8 & 0 \\
\hline
\end{tabular}

Table 2. Habitat suitability and sensitivity to threat factors of different landscape types

\begin{tabular}{c|c|c|c|c|c}
\hline Landscape types & $\begin{array}{c}\text { Habitat } \\
\text { suitability }\end{array}$ & $\begin{array}{c}\text { Aquaculture } \\
\text { pond }\end{array}$ & River & Road & S. alterniflora \\
\hline Aquaculture pond & 0.5 & 0 & 0.5 & 0 & 0.5 \\
River & 0.5 & 0.5 & 0 & 0.8 & 0.5 \\
Mudflat & 0.8 & 0.5 & 0.3 & 0.3 & 0.8 \\
Road & 0 & 0 & 0 & 0 & 0 \\
P. australis & 1 & 0.3 & 0.6 & 0.6 & 0.5 \\
S. alterniflora & 0.5 & 0.5 & 0.5 & 0.7 & 0 \\
S. salsa & 1 & 0.5 & 0.8 & 0.5 & 0.8 \\
\hline
\end{tabular}

The threat factors and habitat suitability are based on whether they are beneficial to the health of habitats of rare species, such as red-crowned cranes. The InVEST model can use either a linear or an exponential model depending on the particular relationship between the distance-decay rate of a threat and the maximum effective distance to a threat. The habitat quality index was calculated as follows (Sharp et al., 2017):

$$
D_{x j}=\sum_{r=1}^{R} \sum_{y=1}^{y_{r}}\left(\frac{w_{r}}{\sum_{i=1}^{R} W_{i}}\right) r_{y} i_{r x y} \beta_{x} s_{j y}
$$

In this equation, $D_{x j}$ is the habitat degradation index, which characterizes the degree of habitat degradation. $R$ is the number of threat factors, $y_{r}$ is the number of grid cells on the threat factor layer, $w_{r}$ is the weight value of the threat factor, $r_{y}$ is the number of raster unit threat factors in the layer, $i_{r x y}$ represents the influence degree of threat factor $r$ in grid $y$ on habitat grid $x, \beta_{x}$ is the degree of protection, and $s_{j r}$ is the sensitivity of the threat factor, which refers to the degree of change of different landscape types under the influence of threat factors with a range of 0 to 1 .

$$
Q_{x j}=H_{j}\left(1-\frac{D_{x j}^{Z}}{D_{x j}^{Z}+k^{Z}}\right)
$$


In this equation, $Q_{x i}$ is the habitat quality index, $H_{j}$ is the habitat suitability, which refers to the suitability of different landscape types for reproduction, habitat and activities of organisms, ranging from 0 to $1 . D_{x i}$ is the degree of habitat degradation, and $k$ is the half-saturation coefficient, which is set to 15 (half of the grid resolution). $z$ is generally set to 2.5 .

\section{Results}

\section{Landscape pattern changes}

The landscape change in Yancheng Coastal Wetland is the result of human activities and natural conditions. Human activities mainly include building dams and roads, artificial breeding, and the introduction of exotic species. The natural conditions include hydrogeomorphic processes, vegetation processes, and soil processes. Natural conditions are a basic driving force for the change of coastal wetland landscapes. Human activities change the natural conditions of coastal wetlands, resulting in the change of the landscape.

The landscape structure of the study area in the YNNR is dominated by $P$. australis marsh, S. salsa marsh, S. alterniflora marsh, and mudflats (Fig. 2). The change of the landscape structure showed that the areas of $P$. australis marsh and $S$. alterniflora marsh were expanding constantly, and the area of the $S$. salsa marsh was obviously decreasing. From 2000 to 2011, the PLAND of the P. australis marsh increased from 5.042\% to $23.601 \%$, that of the S. alterniflora marsh increased from $17.525 \%$ to $34.466 \%$, and that of the $S$. salsa marsh decreased from $36.910 \%$ to $14.414 \%$.

In 2000, 2006, and 2011, the FRAC was 1.046, 1.038, and 1.035, respectively. The continuous decline of the FRAC indicated that the landscape patches in the study area had a trend of regular development. The AI in 2000, 2006, and 2011 was 95.453, 95.553, and 95.244 respectively, showing a slow trend of first rising and then falling with weak change overall. This indicated that the landscape changes in the study area were generally subject to less artificial interference and followed the laws of natural development with a high degree of aggregation among different landscape types. From 2000 to 2011, the SHDI first increased and then decreased. In contrast, the LDI first decreased and then increased. From 2000 to 2006, the proportion of different landscape types developed towards a relatively balanced situation, and the LDI declined due to the expansion of $P$. australis and $S$. alterniflora and the decrease of $S$. salsa marsh. From 2006 to 2011, the $S$. salsa marsh continued to decrease with the continuous expansion of $P$. australis and $S$. alterniflora, the proportion of different landscape types began to develop imbalance again, and LDI increased.

The expansion rate of the $S$. alterniflora marsh was first slow and then became faster. From 2000 to 2006, the annual expansion rate was $163.167 \mathrm{hm}^{2} / \mathrm{a}$, which was significantly lower than the rate of $182.364 \mathrm{hm}^{2} / \mathrm{a}$ from 2006 to 2011 . The variation trend of the FRAC and AI of the S. alterniflora marsh was not obvious from 2000 to 2011. The FRAC values in 2000, 2006, and 2011 were 1.031, 1.049, and 1.030, respectively, which indicated that the shape of the $S$. alterniflora marsh changed little in the natural state. The AI in 2000, 2006, and 2011 was 89.712, 94.605, and 94.336, respectively. The spatial aggregation of the $S$. alterniflora marsh showed consistent characteristics with the overall landscape. 


\section{Habitat quality changes}

From 2000 to 2011, the habitat quality in the study area showed an overall degradation trend (Fig. 3). The habitat quality index (Q) decreased from 0.8183 to 0.7569 (a decrease of $7.5034 \%$ ). From 2000 to 2006, the Q decreased from 0.8183 to 0.7924 with an average annual decrease of 0.0043 . From 2006 to 2011, the Q decreased to 0.7569 with an average annual decrease of 0.0071 . Habitat quality declined more rapidly in the latter period than in the previous period. The decrease of habitat quality was closely related to the expansion speed of the $S$. alterniflora marsh.
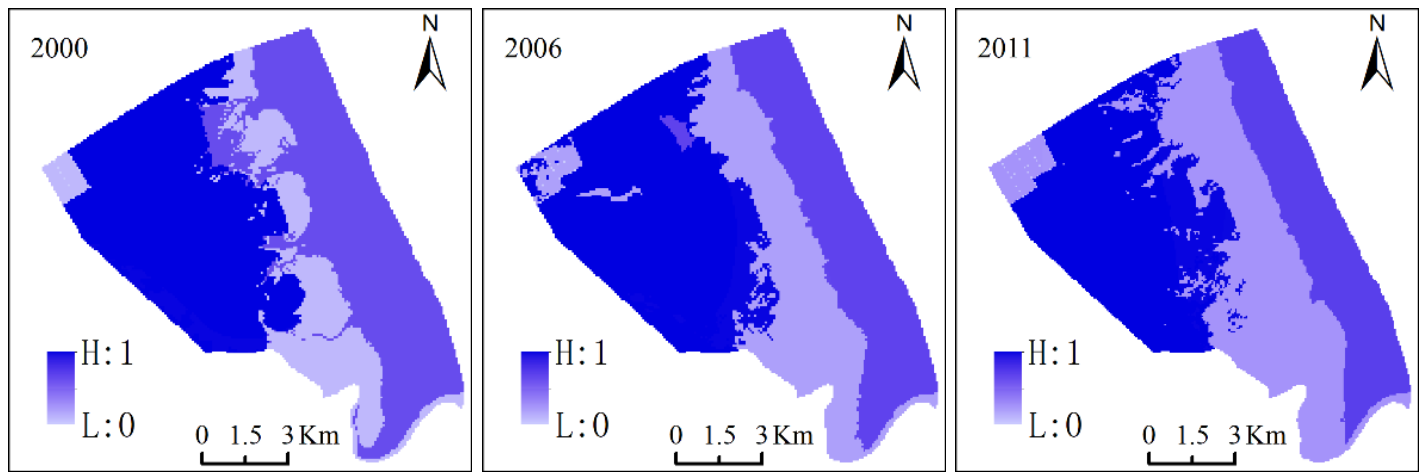

Figure 3. Habitat quality maps in 2000, 2006 and 2011

According to the classification method of equal intervals, the $\mathrm{Q}$ of the study area was divided into four intervals of $0-0.25,0.25-0.5,0.5-0.75$, and $0.75-1$, which indicate poor, general, good, and excellent habitat quality, respectively. As shown in Table 3, the overall habitat quality of the study area was relatively high and was rated as excellent in most areas, followed by general grades and poor grades with no distribution of good grades.

Table 3. Habitat quality classification statistics from 2006 to 2011

\begin{tabular}{c|c|c|c|c|c|c}
\hline \multirow{2}{*}{$\begin{array}{c}\text { Grading } \\
\text { ranges }\end{array}$} & \multicolumn{2}{|c|}{$\mathbf{2 0 0 0}$} & \multicolumn{2}{c|}{$\mathbf{2 0 0 6}$} & \multicolumn{2}{c}{$\mathbf{2 0 1 1}$} \\
\cline { 2 - 7 } & $\begin{array}{c}\text { Area } \\
\left(\times \mathbf{1 0}^{\mathbf{2}} \mathbf{h m}^{\mathbf{2}}\right)\end{array}$ & $\begin{array}{c}\text { Percentage } \\
(\boldsymbol{\%})\end{array}$ & $\begin{array}{c}\text { Area } \\
\left(\times \mathbf{1 0}^{\mathbf{2}} \mathbf{h m}^{\mathbf{2}}\right)\end{array}$ & $\begin{array}{c}\text { Percentage } \\
(\boldsymbol{\%})\end{array}$ & $\begin{array}{c}\text { Area } \\
\left(\times \mathbf{1 0}^{\mathbf{2}} \mathbf{h m}^{\mathbf{2}}\right)\end{array}$ & $\begin{array}{c}\text { Percentage } \\
(\boldsymbol{\%})\end{array}$ \\
\hline $0-0.25$ & 0.070 & 0.064 & 0.114 & 0.104 & 0.200 & 0.182 \\
$0.25-0.50$ & 22.208 & 20.189 & 32.448 & 29.498 & 42.026 & 38.205 \\
$0.50-0.75$ & 0 & 0 & 0 & 0 & 0 & 0 \\
$0.75-1.00$ & 87.722 & 79.747 & 77.438 & 70.398 & 64.774 & 61.613 \\
\hline
\end{tabular}

There was a trend of polarization in habitat quality in the study area. The changes of the proportion of the space area of the three grades were compared. The areas with excellent habitat quality showed a continuous decline, and the proportion of such areas dropped from $79.747 \%$ in 2000 to $61.613 \%$ in 2011 (a decrease of $22.739 \%$ ). The areas with general and poor habitat quality increased. The proportion of areas with poor habitat quality increased from $0.064 \%$ in 2000 to $0.182 \%$ in 2011 (nearly double). Areas of general habitat quality increased from $20.189 \%$ in 2000 to $38.205 \%$ in 2011 (an increase of $89.237 \%$ ). 


\section{Discussion}

\section{Factors affecting the S. alterniflora expansion}

Due to very strict environmental protection policies, human activities in the research area are weak, so the expansion of $S$. alterniflora is mainly driven by natural factors such as climate, hydrological dynamics, geomorphic processes, and vegetation. The main factors are coastal geomorphic processes and the change of plant-cover types. The process of landscape change is continuous and stable. The spatial gradient changes of geomorphic processes and hydrological processes result in the landscape of the study area having a parallel belt pattern extending from north to south and changing from land to sea (Zhang et al., 2013).

The climate in the Yancheng coastal area is basically similar to the east coast of the United States, and the broad intertidal zone is very suitable for the growth of $S$. alterniflora (Callawayet al., 1999; Liu et al., 2004). The coast of the study area is also a typical muddy coast. Under the action of tides and tideways, the average high-water line keeps advancing towards the sea. The subtidal zone and lower intertidal zone are flat, and a tidal creek has developed (Zhang et al., 2006). The fast silting and the wide and gentle beach surface provide a good sedimentary environment for the development of $S$. alterniflora. The tidal amphidromic system of the South Yellow Sea and the tidal advancing system of the East China Sea meet at the Yancheng coast, which makes it difficult for the seeds of $S$. alterniflora to drift with the tides, and they fall on the beach to germinate (Liu et al., 2004).

The geomorphic processes affect the hydrological processes and then affect the physical and chemical properties of the soil, especially the moisture and salinity. Soil is an important driving force of landscape change and has a direct impact on the development and succession of vegetation. A comparison was conducted using elevation data from land to sea in 2002 and 2011 in the study area (Fig. 4) (Hou et al., 2003). The elevation changes from 2002 to 2011 showed an increasing trend overall, and the increasing degree of elevation gradually increased from $P$. australi marsh and $S$. salsa marsh, to $S$. alterniflora marsh. In 2002, the elevation gradually decreased from the land to the sea, but in 2011, the strong ability of S. alterniflora to collect silt led to the elevation being significantly increased in S. alterniflora marsh. As a result, the elevation of the study area had a "U" shape (Hou et al., 2013).

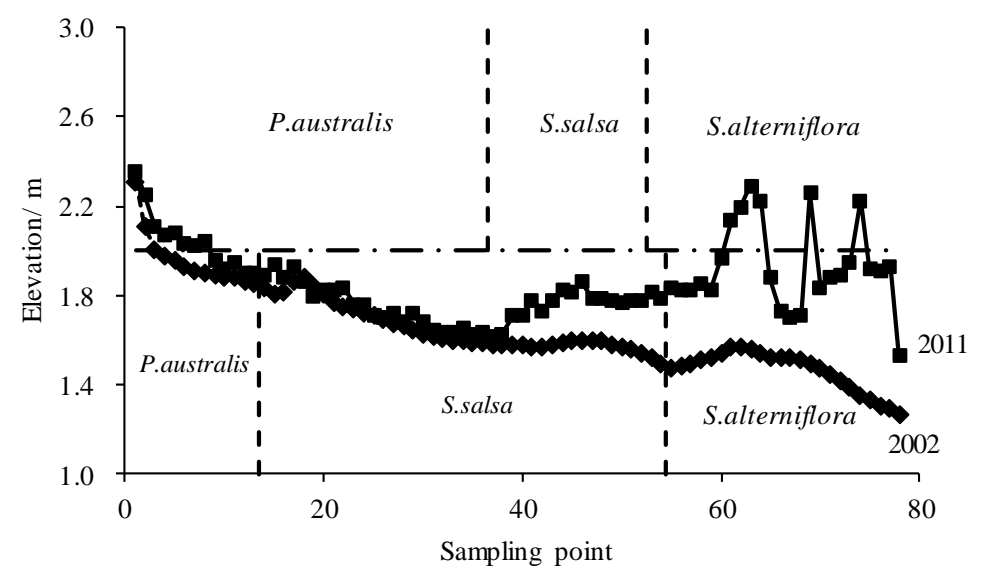

Figure 4. Elevation changes from 2002 to 2011 
Furthermore, the response of vegetation to hydrology and geomorphology promotes the expansion of $S$. alterniflora. S. alterniflora marshes are distributed in the upper of intertidal zone from the upper edge to the average high-tide level and to the lower edge to the average tide level. The frequency of tidal invasion is between $20 \%$ and $80 \%$. The geomorphic processes provide a vast space and environmental conditions for the development of S. alterniflora (Zhang et al., 2004), forming an evolution pattern of a mudflat-S. alterniflora marsh. The native pioneer plant is $S$. salsa, which spreads and expands through seeds. Because of its short plants, a higher frequency of tidal invasion results in smaller plants and fewer branches, which seriously affect the expansion of $S$. salsa to the sea. Its niche cannot reach the tidal flat when the frequency of tidal invasion is more than $20 \%$. Therefore, the expansion ability of $S$. salsa to the sea is far less than that of $S$. alterniflora, and it cannot match the expansion speed of the beach surface in a rapidly silted beach (Zhang et al., 2004; Hou et al., 2013).

As the elevation of the $S$. alterniflora marsh increased, a sharp decrease in the frequency of tides passed through it to reach the $S$. salsa marsh. This restricted the water and salinity conditions needed for the development of the $S$. salsa marsh and promoted the expansion of the $S$. alterniflora marsh to the lower edge of the $S$. salsa marsh. $S$. alterniflora has strong resistance to silting, wind, and waves, and it can grow in most areas of the intertidal zone (Yuan, et al., 2009). Therefore, the expansion of $S$. alterniflora is the fastest, leading to a change of the coastal wetland pioneer community from $S$. salsa to $S$. alterniflora.

S. alterniflora also has two ways of reproduction: sexual and asexual. Sexual reproduction has certain advantages in adapting to different environments. The genetic composition of progeny produced by asexual reproduction is always the same as that of the mother. However, $S$. salsa mainly depends on seed propagation and expansion. The plant is short and has a disadvantageous position in interspecific competition. Therefore, at the upper edge of the $S$. alterniflora marsh, the species can rapidly occupy the growth space when in competition with $S$. salsa, as well as absorb and utilize resources. Thus, it occupies more favorable habitat and forms the new evolution pattern of $S$. salsa marsh S. alterniflora marsh in the study area.

\section{S. alterniflora expansion affecting on landscape patterns}

The spatial distribution, expansion characteristics, and pattern changes of $S$. alterniflora have a significant impact on the coastal wetland landscape. These factors change the composition of the landscape structure, the diversity, and the heterogeneity characteristics (Zhang et al., 2018). Diverse mechanisms of S. alterniflora, such as marginal expansion, external isolation expansion, and tidal creek expansion, have a profound impact on the landscape pattern changes (Wang et al., 2018). The introduction of $S$. alterniflora was successful, and the pioneer community and the dominant population in the coastal wetland gradually changed to $S$. alterniflora. The expansion of $S$. alterniflora changed the landscape succession sequence of the coastal wetland: the succession sequence of mudflat to $S$. alterniflora marsh appeared in the coastal wetland since the introduction of $S$. alterniflora, the succession sequence of mudflat to $S$. salsa marsh gradually disappeared after the formation of the ecotone between $S$. alterniflora and $S$. salsa, and the succession sequence of $S$. salsa marsh to S. alterniflora marsh appeared. From land to sea, the landscape spatial pattern changed from " $P$. australis marsh $-S$. salsa marsh $-S$. alterniflora marsh - mudflat" to " $P$. australis marsh $-S$. alterniflora marsh - mudflat." 
The landscape transfer matrix (Fig. 5) showed that from 2000 to 2006, in the source composition of $S$. alterniflora marsh, mudflats accounted for $34.331 \%$, and $S$. salsa marsh accounted for $2.483 \%$. From 2006 to 2011, the mudflat accounted for $10.591 \%$, and S. salsa marsh accounted for $14.503 \%$. Comparing the two periods, S. alterniflora dominated the expansion towards the sea in the earlier period, while in the later period, $S$. alterniflora expanded to both the ocean and the land. The expansion to the land is greater than the expansion to the sea. From 2000 to 2006, the average width of the $S$. alterniflora marsh increased by $767.393 \mathrm{~m}$, and it pushed forward to the sea about 965 m. From 2006 to 2011, S. alterniflora marsh expanded toward both the sea and the land. It expanded about $325 \mathrm{~m}$ to the sea and $445 \mathrm{~m}$ to the land, and the average width increased by $771.410 \mathrm{~m}$ (Fig. 6).

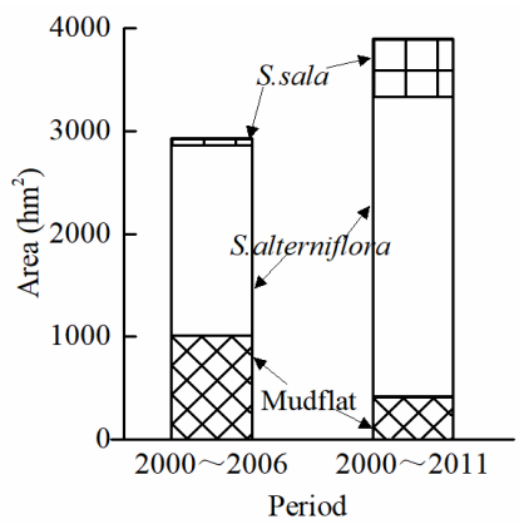

Figure 5. Landscape composition transformed into S. alterniflora

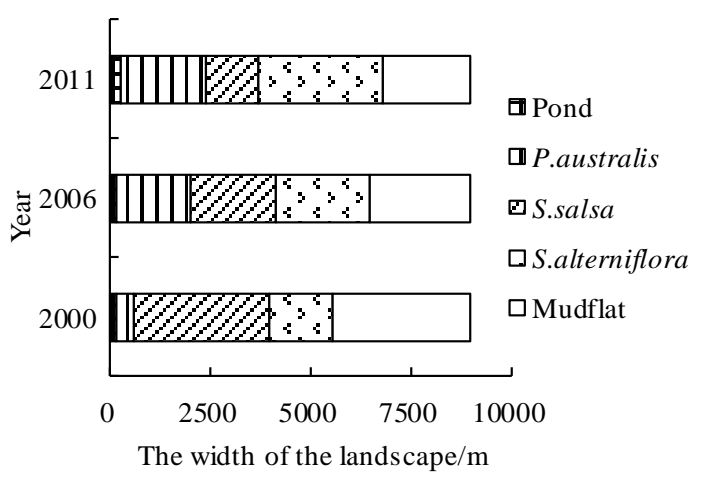

Figure 6. Landscape pattern change of the study area

According to the current development mode (Scenario A), by 2020, the PLAND of $S$. alterniflora marsh would increase to $51.522 \%$, and the expansion rate would reach 210 . $357 \mathrm{hm}^{2} / \mathrm{a}$, while the PLAND of $S$. salsa marsh would decrease to $2.999 \%$ under twoway compression. In terms of the spatial pattern (Fig. 7), the S. alterniflora marsh would basically connect with the $P$. australis marsh, and the competition between the $P$. australis population and the $S$. alterniflora population for spatial resources would be the most intense in the middle tide wetland. Even in the local area of high-tide beaches, the $S$. alterniflora population could form small-scale patches and spread to the $P$. australis population (Pan et al., 2012). 

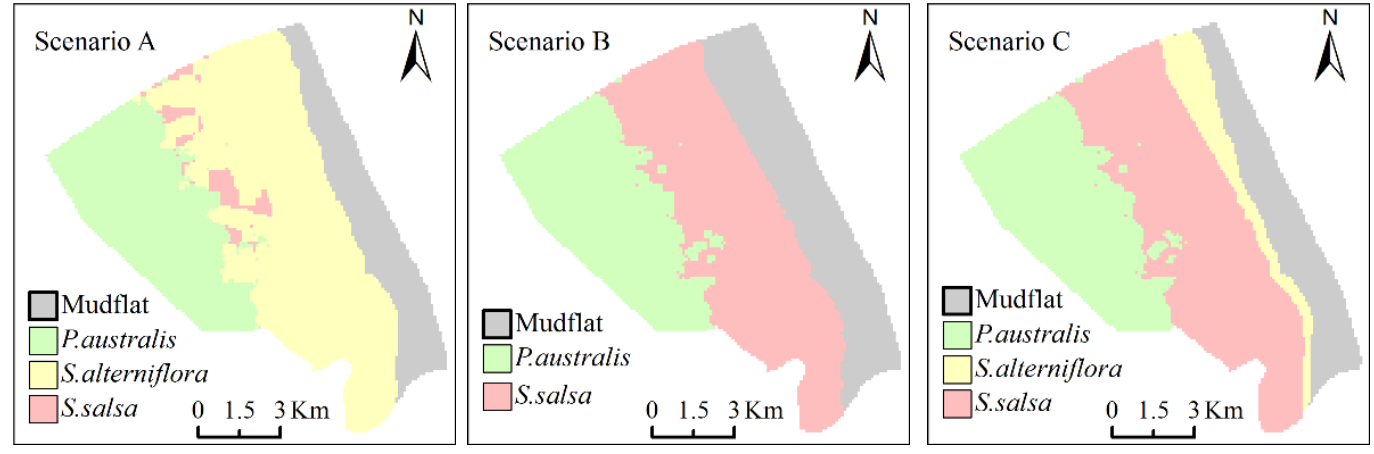

Figure 7. Simulation results of landscape pattern in different scenarios

The expansion of $S$. alterniflora gradually formed a single plant community, which reduced the biodiversity of bird habitat and the number of suitable habitats (Wang et al., 2019). Furthermore, the structure of bird community tended to be simplified (Guntenspergen et al., 2006). The native species of $S$. salsa played an important role in the process of overwintering and reproduction for birds. Thus, it is necessary to take measures for the protection and restoration of the $S$. salsa marsh and to delay the expansion of S. alterniflora (Zhang et al., 2017). Scenario B examined the removal of $S$. alterniflora. By 2020, the PLAND of $S$. salsa marsh would be recovered to $43.832 \%$, and S. alterniflora marsh would disappear (Fig. 7). In Scenario C, a certain scale of $S$. alterniflora would be reserved to protect the coast, and it would no longer expand to the direction of $S$. salsa marsh. Moreover, artificial measures would be taken to restore the evolution sequence from mudflat to $S$. salsa marsh. The results showed that by 2020 , the PLAND of $S$. salsa marsh would be recovered to $43.865 \%$, and the PLAND of $S$. alterniflora marsh would be controlled to $8.678 \%$ (Fig. 7). The landscape pattern index of the three models were compared, and the following results were obtained (Fig. 8): SHDI, scenario $\mathrm{C}>$ scenario $\mathrm{A}>$ scenario $\mathrm{B}$; the difference of the FRAC was small, scenario A > scenario C > scenario B; SHEI, scenario B > scenario C > scenario A; AI: scenario B (98.0113) > scenario C (97.4472) > scenario A (97.0993).

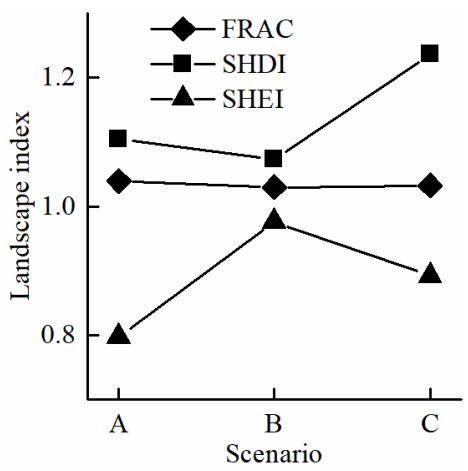

Figure 8. Landscape index scenario simulation results

\section{S. alterniflora expansion affecting habitat quality}

The expansion of $S$. alterniflora changed the vegetation structure, geomorphic pattern, and hydrological processes in the study area, as well as the service function of 
the ecosystem. The benthos of S. alterniflora is rich, and the height of the vegetation on the surface is often more than $1.5 \mathrm{~m}$. But the vegetation coverage of $S$. alterniflora is up to $90-100 \%$, and there is no other vegetation among the plants after two or more years of growth. Consequently, S. alterniflora marsh is unsuitable for the habitat and reproduction of birds (Deng et al., 2009).

Furthermore, the blocking of S. alterniflora from the tide inhibited the growth of $S$. salsa (Shen et al., 2003) and had adverse effects on the birds that depend on the propagation and habitat of the $S$. salsa community, such as Saunders's gull, Sternahirundo, S. albifrons, and Trigatotanus. The results showed that with the expansion of $S$. alterniflora, the Q values of the study area showed a significant decline. Based on the remote sensing image analysis of YNNR from 1983 to 2017, it was found that the $\mathrm{Q}$ was negatively related to the expansion of $S$. alterniflora. Faster expansion of $S$. alterniflora correlated with a faster decline of habitat quality. In scenario A, $S$. alterniflora would continue to expand, and the Q would decrease to 0.7074 . In scenario B, S. alterniflora would be removed, and the Q would increase to 0.9463. In scenario C, $S$. alterniflora would be controlled to a certain scale, and the Q would increase to 0.9198 (Figs. 9 and 10).

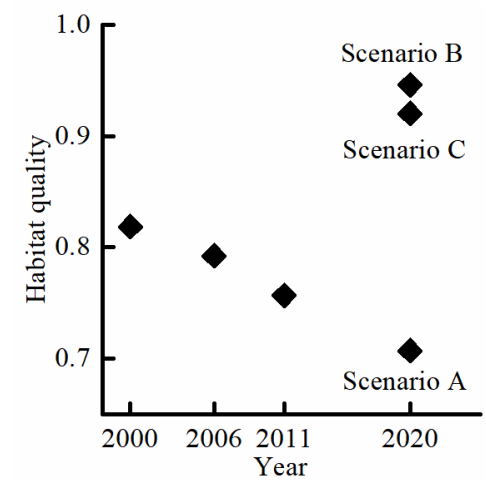

Figure 9. The value changes of habitat quality

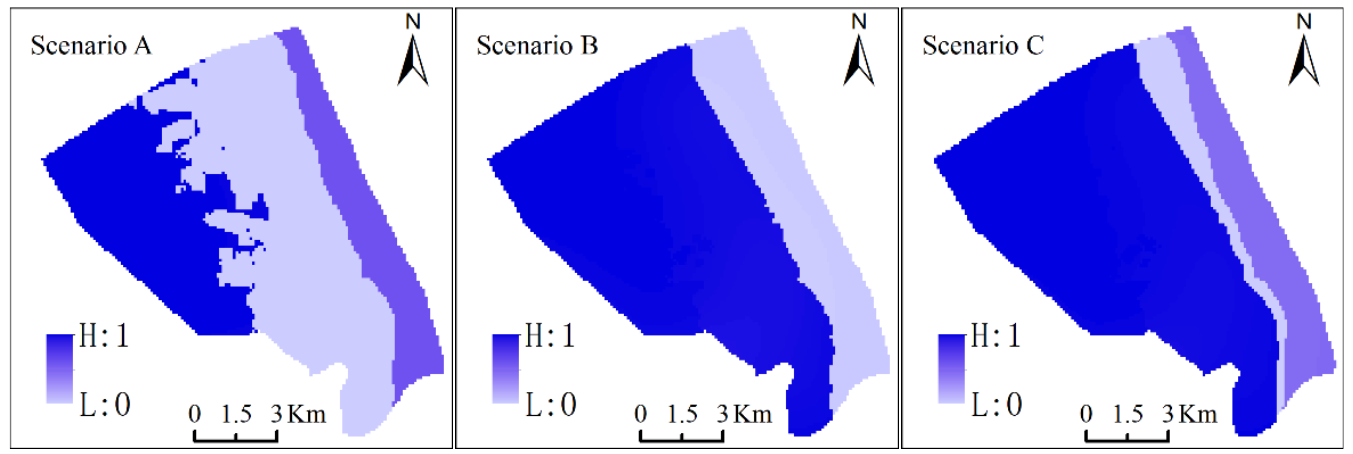

Figure 10. Simulation results of habitat quality in different scenarios

Based on the results, rich landscape diversity should be maintained along with the stability of the coast, and the wetland habitat quality should be improved. Scenario C would be a relatively ideal model for three reasons. First, it would help to retain a certain scale of $S$. alterniflora marsh, prevent erosion from tidal water on the coast, and 
promote the deposition of the beach surface, although further study is needed to determine the appropriate scale of S. alterniflora. Secondly, it would protect the local species $S$. salsa and improve the suitability of habitat areas for rare species such as the red crowned crane. Thirdly, it would maintain the landscape diversity; the SHDI of scenario $\mathrm{C}$ was the highest and reached 1.236.

Ecological engineering measures, physical engineering measures, and biological measures could be effective means to control the expansion of S. alterniflora based on maintaining the integrity and continuity of the coastal ecosystem. In addition, some research has shown that the changes in habitats caused by inventors could limit the inventors over time because the acquisition of habitat changes created certain habitat properties that exceeded the optimal range for inventors (Tang et al., 2012).

\section{Conclusions}

This study quantitatively evaluated the effects of the expansion of S. alterniflora on the landscape pattern and habitat quality in the YNNR. The results showed that the rapid expansion led to a sharp reduction of the local species of $S$. salsa, which has posed a serious threat to the biodiversity. The landscape pattern gradually changed from " $P$. australis marsh $-S$. salsa marsh $-S$. alterniflora marsh - mudflat" to " $P$. australis marsh - S. alterniflora marsh - mudflat." It affected the living environment of species that use the $S$. salsa community as a habitat and breeding ground. With the expansion of S. alterniflora, the habitat quality decreased significantly. Controlling the expansion of $S$. alterniflora and restoring the $S$. salsa marsh would be an ideal choice for the sustainable development of the YNNR. In the future, it will be an important task for the YNNR to control the $S$. alterniflora expansion and restore the $S$. salsa marsh. On one hand, we need to study the suitable scale of $S$. alterniflora in order to play its ecological function. On the other hand, we need to explore the approach of utilization for $S$. alterniflora and give full play to the comprehensive benefits.

Acknowledgements. This research was supported by National Natural Science Foundation of China (No.41771199, No.41501567), Basic Research Project of Jiangsu Province, China (No. BK20171277), Natural science research projects of colleges and universities in Jiang Province (No.18KJD170001) and Qing Lan Project in Jiangsu University of China.

\section{REFERENCES}

[1] Ayres, D. R., Strong, D. R. (2002): The spartina invasion of San Francisco Bay. Aquatic Nuisance Species Digest 4: 38-40.

[2] Ayres, R. D., Smith, D. L., Zaremba, K., Klohr, S., Strong, D. R. (2004): Spread of exotic cordgrasses and hybrids (Spartina sp.) in the tidal marshes of San Francisco Bay, California, USA. - Biological Invasions 6: 221-231.

[3] Callaway, J. C., Josselyn, M. N. (1999): The introduction and spread of smooth cordgrass (Spartina-alterniflora) in south San Francisco Bay. - Estuaries 15: 218-226.

[4] Deng, Z. F., Deng, Z. W., An, S. Q., Wang, Z. S., Liu, Y. H., Oouyang, Y., Zhou, C. F., Zhi, Y. B., Li, H. L. (2009): Habitat choice and seed-seedling conflict of Spartina alterniflora on the coast of China. - Hydrobiologia 630: 287-297.

[5] Dong, B., Song, G. X., Xie, Y. M., Xie, Y. M., Pei, E. L., Wang, T. H. (2010): Research on the habitat-selection of Reed Parrotbill (Paradoxornis heudei) during the winter in Chongming Dongtan, Shanghai. - Acta Ecologica Sinica 30: 4351-4358. 
[6] Fang, R. J., Shen, Y. M., Wu, D. L. (2014): Landscape pattern change in different sedimentary coastal areas of Yancheng, Jiangsu. - Chinese Journal of Ecology 4: 10961103.

[7] Guntenspergen, G. R., Nordby, J. C. (2006): The impact of invasive plants on tidal-marsh vertebrate species, common reed (Phragmites australis) and smooth cordgrass (Spartina alterniflora) as case studies. - Terrestrial Vertebrates of Tidal Marshes Evolution Ecology \& Conservation 32: 229-237.

[8] Hou, M. H., Liu, H. Y., Zhang, H. B., Wang, C., Tan, Q. M. (2013): Influences of topographic features on the distribution and evolution of landscape in the coastal wetland of Yancheng. - Acta Ecologica Sinica 33: 3765-3773.

[9] Landis., J. R., Koch., G. G. (1997): The measurement of observer agreement for categorical data. - Biometrics 33: 159-174.

[10] Liao, C. Z., Luo, Y. Q., Jiang, L. F., Zhou, X. H., Wu, X. W., Chen, J. K., Li, B. (2007): Invasion of Spartina alterniflora enhanced ecosystem carbon and nitrogen stocks in the Yangtze estuary, China. - Ecosystems 10: 1351-1361.

[11] Liu, C. Y., Zhang, S. Q., Jiang, H. X., Wang, H. (2009): Spatiotemporal dynamics and landscape pattern of alien species Spartina alterniflora in Yancheng coastal wetlands of Jiangsu Province. - Chinese Journal of Applied Ecology 20: 901-908.

[12] Liu, D. W., Zhang, Y. L., Sun, Y., Lu, S. C., Cheng, H., Mu, S. J., Lu, C. H. (2016): Population dynamics and habitat selection of overwintering Red-Crowned Crane in coastal wetland of Yancheng, Jiangsu Province. - Journal of Ecology and Rural Environment 32: 473-477.

[13] Liu, J. E., Zhou, H. X., Qin, P., Zhou, J. (2007): Effects of Spartina alterniflora salt marshes on organic carbon acquisition in intertidal zones of Jiangsu Province, China. Ecological Engineering 30: 240-249.

[14] Liu, Q. S., Li, Y. F., Zhu, X. D. (2003): Characteristics of coastal wetland ecosystem and their healthy design, a case study from Yancheng Nature Reserve, Jiangsu Province, China. - Acta Oceanologica Sinica 25: 43-148.

[15] Liu, Y. X., Li, M. C., Zhang, R. S. (2004): Approach on the dynamic change and influence factors of S. alterniflora Loisel salt-marsh along the coast of the Jiangsu Province. - Wetland Science 2: 116-121.

[16] Monserud., R. A., Leemans., R. (1992): Comparing global vegetation maps with the Kappa statistic. - Ecological Modelling 62: 275-293.

[17] Neira, C., Grosholz, E. D., Levin, L. A., Blake, R. (2006): Mechanisms generating modification of benthos following tidal flat invasion by a Spartina hybrid. - Ecological Applications 16: 1391-1404.

[18] Pan, Y., Li, D. Z., Yuan, Y., Xu, J., Gao, J. J., Lu, Y. Y. (2012): Distribution pattern of Phragmites australis and Spartina alterniflora populations in Chongming Dongtan wetland and its correlation with habitat. - Journal of Plant Resources and Environment 21: $1-9$.

[19] Pimentel, D., Lach, L., Zuniga, R., Morrison, D. (2000): Environmental and economic costs of nonindigenous species in the United States. - Bioscience 50: 53-65.

[20] Schindler, S., von Wehrden, H., Poirazidis, K., Wrbka, T., Kati, V. (2013): Multiscale performance of landscape metrics as indicators of species richness of plants, insects and vertebrates. - Ecological Indicators 31: 41-48.

[21] Sharp, R., Chaplin-Kramer, R., Wood, S., Guerry, A., Tallis, H., Ricketts, T. (2017): InVEST 3.2.0 User's Guide, Integrated Valuation of Environmental Services and Tradeoffs. - The Natural Capital Project, Stanford.

[22] Sharp, S. J., Angelini, S. (2019): The role of landscape composition and disturbance type in mediating salt marsh resilience to feral hog invasion. - Biological Invasions 21: 28572869.

[23] Shen, Y. M., Zhang, R. S., Wang, Y. H. (2003): The tidal creek character in salt marsh of Spartina alterniflora Loisel on strong tide coast. - Geographical Research 22: 520-527. 
[24] Tang., L., Yang, G. C., Wang, C. H., Zhao, B., Li, Bo. (2012): A plant invader declines through its modification to habitats. A case study of a 16-year chronosequence of Spartina alterniflora invasion in a salt marsh. - Ecological Engineering 49: 181-185.

[25] Vitousek, P. M., D'antonio, C. M., Loope, L. L., Marcel, R., Westbrooks, R. (1996): Introduced species, a significant component of human-caused global change. - New Zealand Journal of Ecology 21: 1-16.

[26] Wang, C., Liu, H. Y. (2014): The impact of spartina alterniflora expansion on vegetation landscapes in the Yancheng tidal flat wetland. - Resources Science 36: 2413-2422.

[27] Wang, J., Liu, H. Y., Li, Y. F., Liu, L., Xie, F. F. (2018): Recognition of spatial expansion patterns of invasive Spartina alterniflora and simulation of the resulting landscape changes. - Acta Ecologica Sinica 38: 5413-5422.

[28] Wang, J., Liu, H. Y., Li, Y. F., Liu, L., Xie, F. F., Lou, C. R., Zhang, H. B. (2019): Effects of Spartina alterniflora invasion on quality of the red-crowned crane (Grus japonensis) wintering habitat. - Environmental Science and Pollution Research 26: 21546-21555.

[29] Wang, J. Q., Zhang, X. D., Nie, M., Fu, C. Z., Chen, J. K., Li, B. (2008): Exotic Spartina alterniflora provides compatible habitats for native estuarine crab Sesarma dehaani in the Yangtze River estuary. - Ecological Engineering 34: 57-64.

[30] Yuan, H. W., Li, S. Z., Zheng, H. Z., Fang, Z. Y. (2009): Evaluation of the influences of foreign $S$. alterniflora on ecosystem of Chinese coastal wetland and its countermeasures. - Marine Science Bulletin 28: 122-128.

[31] Zhang., H. B. (2018): Landscape Pattern Change and Ecological Process Response in Yancheng Coastal Wetland. - Science Press, Beijing.

[32] Zhang, H. B., Liu, H. Y., Hou, M. H. (2013): Spatiotemporal characteristics of Spartina alterniflora marsh change in the coastal wetlands of Yancheng caused by natural processes and human activities. - Acta Ecologica Sinica 33: 4767-4775.

[33] Zhang., H. B., Liu., H. Y., Hou., M. H., Li., Y. F. (2014): Building model based on processes and simulating landscape change in the coastal wetlands-A case study of the core area in Yanchegn Natural Reaerve. - Journal of Natural Resources 29: 1105-1115.

[34] Zhang, J. C., He, D. J., You, W. B., Deng, X. P., Zhang, F. Y., Liu, J. C. (2018): Invasion impact of Spartina alterniflora on the landscape of coastal wetland in Xiapu County. Journal of Forest and Environment 38: 302-308.

[35] Zhang, R. S., Shen, Y. M., Lu, L. Y., Yan, G. S., Wang, Y. H., Li, J. L., Zhang, Z. L. (2004): Formation of S. alterniflora salt marshes on the coast of Jiangsu Province, China. - Ecological Engineering 23: 95-105.

[36] Zhang, X. Q., Wang, G. X., Wang, Y. H., Wang, Z. L. (2006): The changes of erosion or progradation of tidal flat and retreat or extension of wetland vegetation of the Yancheng coast, Jiangsu. - Marine Sciences 30: 35-39.

[37] Zhang., Y., Sun, Y., Lu, C. H., Zhang, Y. L., Lu, S. C. (2017): Pattern of wintering bird community in three habitats after invasion of Spartina alterniflora in Yancheng National Nature Reserve. - Wetland Science 15: 433-440. 